\title{
Assessment of revegetation with waste coal on the reclaimed sites in the Kemerovo Region - Kuzbass
}

\author{
Irina Semina ${ }^{1 *}$, Vladimir Androkhanov ${ }^{2}$, and Sergey Solovyev ${ }^{2}$ \\ ${ }^{1}$ Siberian State Industrial University, Novokuznetsk, 654007, Russia \\ ${ }^{2}$ Institute of Soil Science and Agrochemistry SB RAS, Novosibirsk, 630090, Russia
}

\begin{abstract}
The paper presents the results of research and assessment of the revegetation degree in reclaimed areas using coal preparation waste in the Kemerovo region - Kuzbass. Reclamation of disturbed lands was carried out by backfilling the worked-out pits of the former coal mine with coal preparation waste and forming a root layer on the leveled surface of the waste using materials of the fertile soil layer (FSL) and potentially fertile rocks (PFR). During the field survey of reclamation sites, it was found that when sowing perennial grasses (Bromopsis inermis, Medicago sativa, etc.) or planting trees and shrubs (Hippophae rhamnoides, Pinus sylvestris, etc.) on the formed root layer from the PFR and / or FSL, favorable conditions are created for the formation of the primary phytocenosis in the reclaimed areas. The studies also showed that in reclaimed areas using a fertile soil layer for the formation of a root layer, a gradual restoration of soil properties is recorded in the surface covered layers, which in some parameters are close to natural soils common in the adjacent territories.
\end{abstract}

\section{Introduction}

The soil and vegetation cover of the Kemerovo region - Kuzbass is rich and varied. Mining companies, in accordance with the Coal Industry Development Program, are increasing their production capacities and have a technogenic impact on the environment.

The first attempts to neutralize the consequences of the negative impact of mining, including coal mining, on the environment through the purposeful formation of vegetation cover on disturbed lands began to be made in the industrially developed countries of Europe at the beginning of the $20^{\text {th }}$ century [1]; on the territory of the former Soviet Union, this process began in the 50's of the XX century in Donbass [2]. It should be noted that abroad the work on the reclamation of technogenic landscapes through the formation of vegetation cover pursued agricultural and forestry goals, but at the end of the $20^{\text {th }}$ century, more attention was paid to the ecological component. Among other things, in the reclamation of disturbed lands there is a move from a simple seeding of disturbed areas with grasses and planting of woody plants to a more meaningful - an integrated approach, which consists in the development of individual reclamation projects taking into account

*Corresponding author: semina.i@mail.ru 
many factors, including climate, relief, level of fertility and physical properties of rocks, etc. [2]. Rich experience has been accumulated in the restoration of soil and vegetation cover in technogenically disturbed territories in Russia and abroad [3-12]. To restore disturbed lands, various reclamation technologies are used, taking into account the specifics of local natural resources, physical and agrochemical properties of substrates, and special attention is paid to the selection of suitable plant species for the formation of vegetation cover. Still, the main condition for successful reclamation of technogenic landscapes is the creation of favorable edaphic conditions for the formation of primary vegetation cover. A lot of works on various types of disturbed territories located in various climatic conditions are devoted to these issues [13-16]. Nevertheless, studies on the restoration of vegetation cover in reclaimed areas with coal preparation wastes are relevant.

Purpose of the work: to study the processes of restoration of vegetation cover in reclaimed areas with waste of coal enrichment and assess the phytodiversity in areas with different root layer.

\section{Materials and methods}

The reclaimed sites, in administrative terms, are located on the territory of LeninskKuznetsk urban district, which is located in the western part of the Kemerovo Region Kuzbass, in the center of the Kuznetsk depression - within the Kuzbass coal basin. In natural terms, the investigated territory belongs to the Central forest-steppe region of the Kuznetsk depression, which is the steppe part of the region. The forest-steppe nature of the landscape is more typically expressed along the region periphery and on the right bank of the river Iney. The area between the river Iney and Salair Ridge is now an almost pure steppe with small and extremely rarely scattered birch copses. Reclamation sites differ in age (3-9 years) and in the peculiarities of the root layer formation on the surface of the planned waste dump.

The technical stage of disturbed lands reclamation was carried out by backfilling the worked-out pits of the former open-pit mine with waste from coal preparation and forming on the leveled surface a recultivation layer with a thickness of $20-40 \mathrm{~cm}$ using materials of the fertile soil layer (FSL) and potentially fertile rocks (PFR). In accordance with the classification of technogenic landscape soils, the reclamation sites are presented: without applying PFR and FSL to the dump surface (point 1 - initial embryozem, site age -7 years), with PFR applied to the surface (point 2 - lithogenic technosol, site age -3 years ), with application of PFR and FSL to the surface of the dump (point 3, humusogenic undifferentiated technosol, site age -7 years), with application of the mixture to the surface of the dump PFR and FSL (point 4 - humusogenic undifferentiated technosol, site age -7 years) and layer-by-layer application of PFR and PSP to the surface of the dump (point 5 humus differentiated technosol, site age -9 years). Sections are laid on a horizontal surface in the central part of the site. Control is the leached chernozem (point 6). All selected areas are characterized by a flat, undulating relief with shallow depressions.

According to the study results of the physical properties of the young soils and substrates surface layers, it was found that technosol are characterized by increased density (in the lower part of the filled layer, the density in comparison with the control option is on average more than $1.30 \mathrm{~g} / \mathrm{cm}^{3}$ ). The density of the surface layer of the initial embryozem (the area without filling the PFR and FSL) is $1.56 \mathrm{~g} / \mathrm{cm}^{3}$, which is due to the properties of the technogenic substrate, overconsolidation during planning work with heavy equipment at the reclamation technical stage and the underdevelopment of the vegetation cover in this area. According to the granulometric composition and to the Kachinsky classification, the material of the fine-grained part of the substrates varies widely from light loams to clays. The content of physical clay particles (fraction less than $0.01 \mathrm{~mm}$ ) in the fine-grained part 
of the underlying rocks (horizon D) varies within $28-38 \%$ and is characterized as medium loam. However, it should be borne in mind that the amount of fine earth in this substrate does not exceed $15 \%$. This is due to the high rockiness of these substrates, which are poorly destroyed in the process of preparation, reclamation and subsequent placement. From the analysis of reclaimed soils physical properties, it follows that the $\mathrm{pH}$ values vary in the range from 7.9 to 9.9 , which indicates an alkaline reaction of the soil solution. The highest $\mathrm{pH}$ values of 9.00 to 9.9 are typical for the horizons of the underlying rocks, consisting of coal preparation wastes. The $\mathrm{pH}$ value is determined by the mineralogical composition of the rock. The bulk of the host rocks are sandstones, siltstones, mudstones, and carbonaceous particles.

The rocks are cemented by carbonate, clay-carbonate, carbonate-clay, and carbonaceous-clay compositions. Carbonates are represented by grains of calcite, siderite and dolomite. Siltstones are also characterized by carbonatization. The content of watersoluble salts in young soils and substrates in the dry residue is generally from 0.039 to $0.118 \%$, the amount of toxic salts does not exceed $0.01 \%$. In lithogenic technozem (point 2 ) at a depth of 6-17 cm, an increase in the amount of toxic salts up to $0.202 \%$ was recorded (hydrocarbonates prevail $-3.00 \mathrm{mmol} / 100 \mathrm{~g}$, calcium salts $-2.22 \mathrm{mmol} / 100 \mathrm{~g}$, sulfates $0.228 \mathrm{mmol} / 100 \mathrm{~g}$ ) and humusogenic undifferentiated technozem (point 4) at a depth of 20$30 \mathrm{~cm}$, the sum of toxic salts is $0.218 \%$ (bicarbonates prevail $-2.50 \mathrm{mmol} / 100 \mathrm{~g}$, sodium salts $-2.53 \mathrm{mmol} / 100 \mathrm{~g}$ ). To assess the degree of restoration of the vegetation cover of the reclaimed sites, a geobotanical description was carried out on five test sites with a size of $100 \mathrm{~m}^{2}$, characterized by different properties, of the root layer [7]. Also, in order to identify the degree of restoration of the vegetation cover of the reclaimed areas, an undisturbed phytocenosis located near the reclaimed areas was investigated. Geobotanical descriptions were carried out on standard forms for their systematization and standardization of the data obtained.

Samples of young soils and substrates of technogenic landscapes were studied in the analytical laboratories of West Siberian Testing Center JSC, Institute of Soil Science and Agrochemistry SB RAS, SibSIU.

\section{Results and discussion}

When examining the vegetation cover of the reclaimed sites by the method of geobotanical descriptions (GBD), the following features were noted.

Reclaimaed site No. 2, of 3 years old, with dumping of light loams (PFR) as a root layer, without sowing grasses (Fig. 1), is characterized by a large species diversity - 34 species (the predominant share of ruderal species is characteristic of the initial stages of overgrowth, GBD of site No. 2), but with a very small projective cover - no more than $15 \%$.

The dominants are Artemisia absinthium L. and Elytrigia repens (L.) Nevski. The tree layer is represented by one specimen of undergrowth Ulmus pumila L. On two sites (No. 3 and 4) in 2013, the biological stage of reclamation was carried out using two methods. The first method - by sowing Bromopsis inermis (Leyss.) Holub and Medicago sativa L. (GBD site No. 4), the second - planting Hippophae rhamnoides L. and Pinus sylvestris L. (GBD site No. 3, Fig. 2). When sowing perennial grasses, the projective cover reaches $90 \%$, the species diversity is 16 species, dominated by Bromopsis inermis (Leyss.) Holub, Elytrigia repens (L.) Nevski, and Poa stepposa (Krylov) Roshev. 


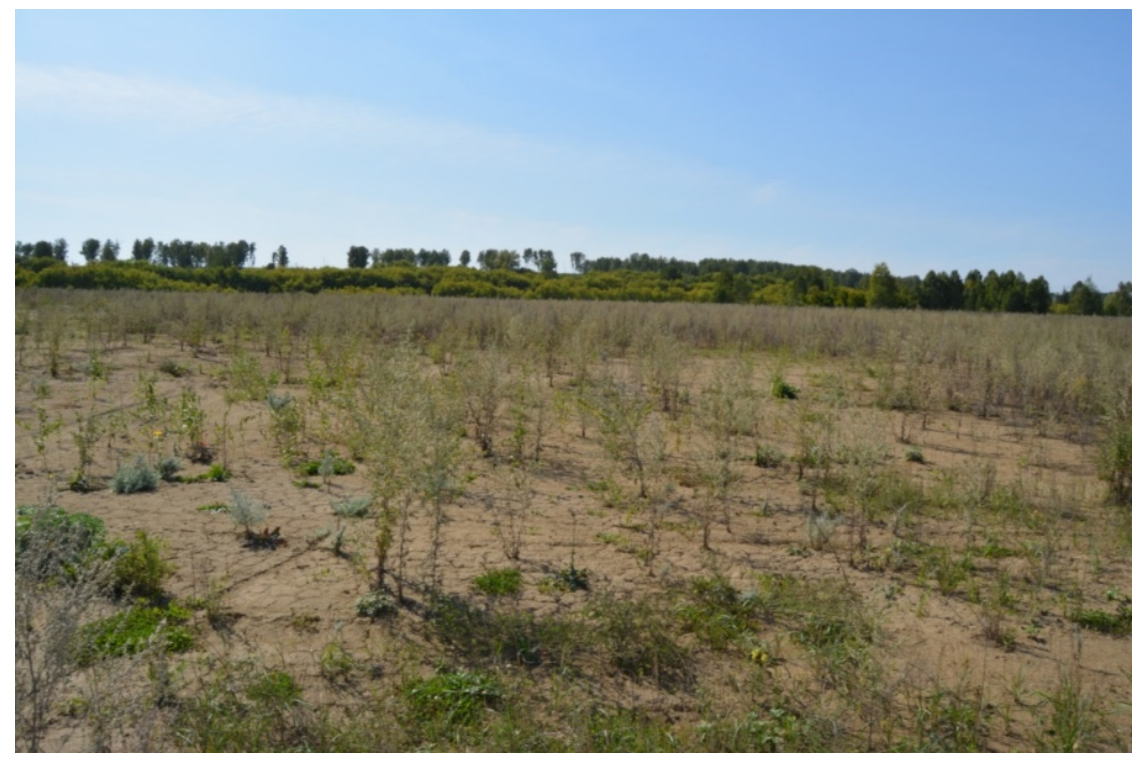

Fig. 1. Vegetation cover on site number 2.

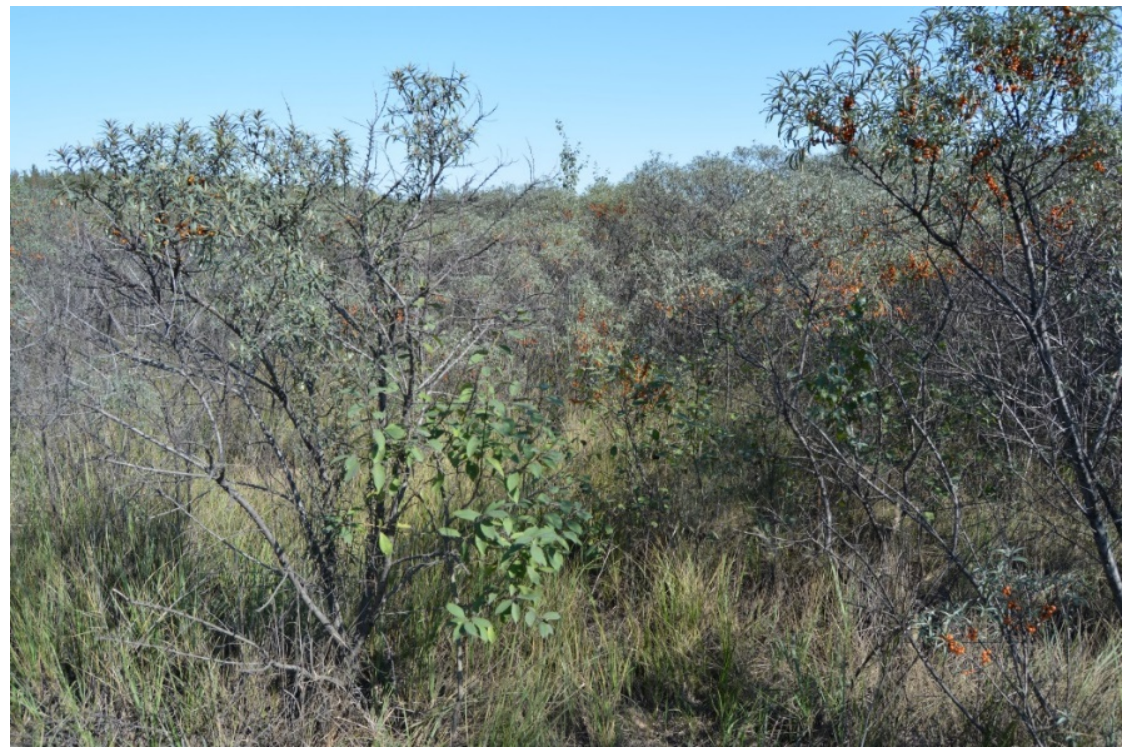

Fig. 2. Vegetation cover on site No. 3 .

After seven years of reclamation, Medicago sativa L. in this area completely dropped out of the vegetation cover. On the site with sandthorn and pine planting, the projective cover is $85 \%$ with a species diversity of 15 species, among which Calamagrostis epigeios (L.) Roth dominates, and in the shrub layer - Hippophae rhamnoides L. Among the tree layer, the previously planted Pinus sylvestris L. turned out to be of little use for these conditions, although it retained its presence. It should be noted that Betula pendula Roth, Populus tremula L., and Acer negundo L. appeared in the tree layer. Among other things, in 
these two sites there is a ground layer, represented by mosses and making up $10 \%$ of the projective cover, and a significant activity of the animal world was found in the sites, in particular, in the first case (the predominance of the herbaceous layer), a significant number of rodent burrows are found, in the second (the predominance of the tree layer), a large number of anthills.

In 2013, a site from coal preparation waste and mine rocks was planned (GBD site No. 1, Fig. 3), where the biological stage of reclamation was not carried out, but only the technological stage of reclamation was carried out. At the time of the survey, a significant species diversity was recorded in this area -20 species with a projective cover of no more than $7 \%$.

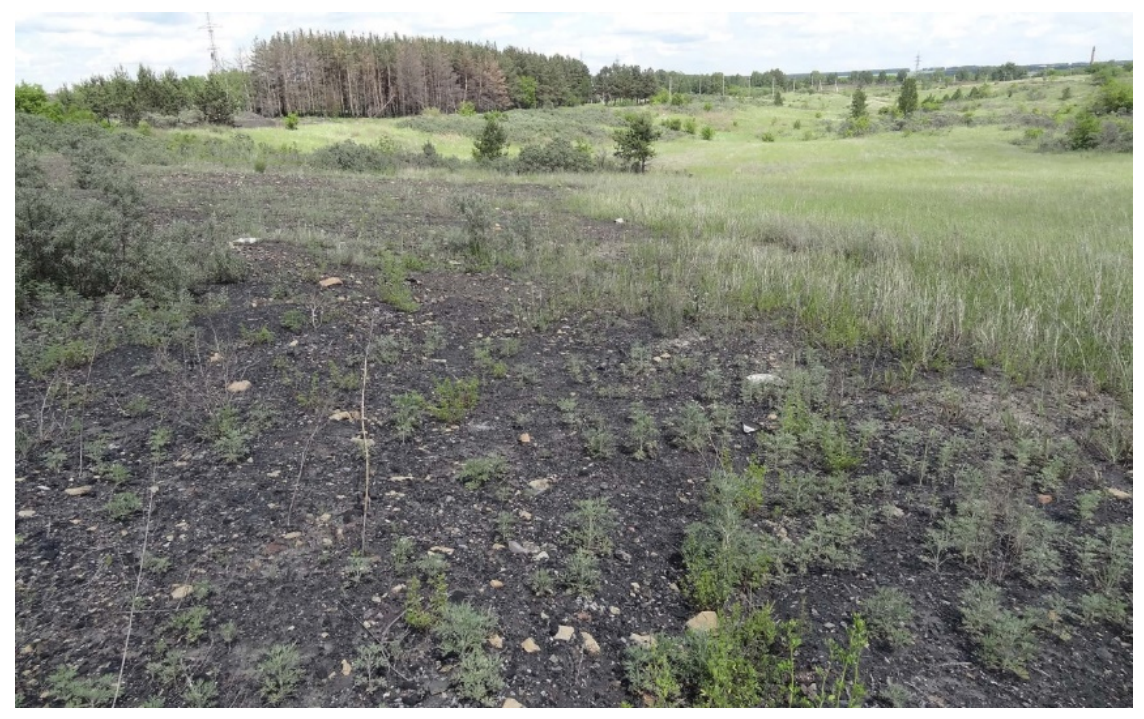

Fig. 3. Vegetation cover on site No. 1

The arboreal and shrub layers are represented by several specimens of Acer negundo L., Pinus sylvestris L., Populus nigra L., and Hippophae rhamnoides L., and the herbaceous layer is represented by forbs of ruderal species. It is necessary to emphasize the fact that all plants represented on this site are in a depressed state, which may indicate unfavorable edaphic conditions of the root layer.

The vegetation cover at the reclamation site (GBD site No. 5), carried out in 2011 by sowing Bromopsis inermis (Leyss.) Holub, is represented by 18 species of herbaceous plants with a projective cover of $80 \%$. The dominants are Calamagrostis epigeios (L.) Roth, Dactylis glomerata L., Poa stepposa (Krylov) Roshev. and Bromopsis inermis (Leyss.) Holub. The ground layer is also represented by mosses with a projective cover of $10 \%$. On the territory of the surveyed area, there is a significant number of rodent burrows.

A site near the study area was chosen as a control site (steppe meadow) (GBD control site No. 6, Fig. 4). Its vegetation is represented by a herbaceous layer. The projective cover is $95 \%$, and the species diversity includes 31 species. The dominants are Artemisia glauca Pall. ex Willd., Phlomoides tuberosa (L.) Moench, Filipendula vulgaris Moench, and others. On the site the activity of the animal world, in particular several anthills, is also noted. 


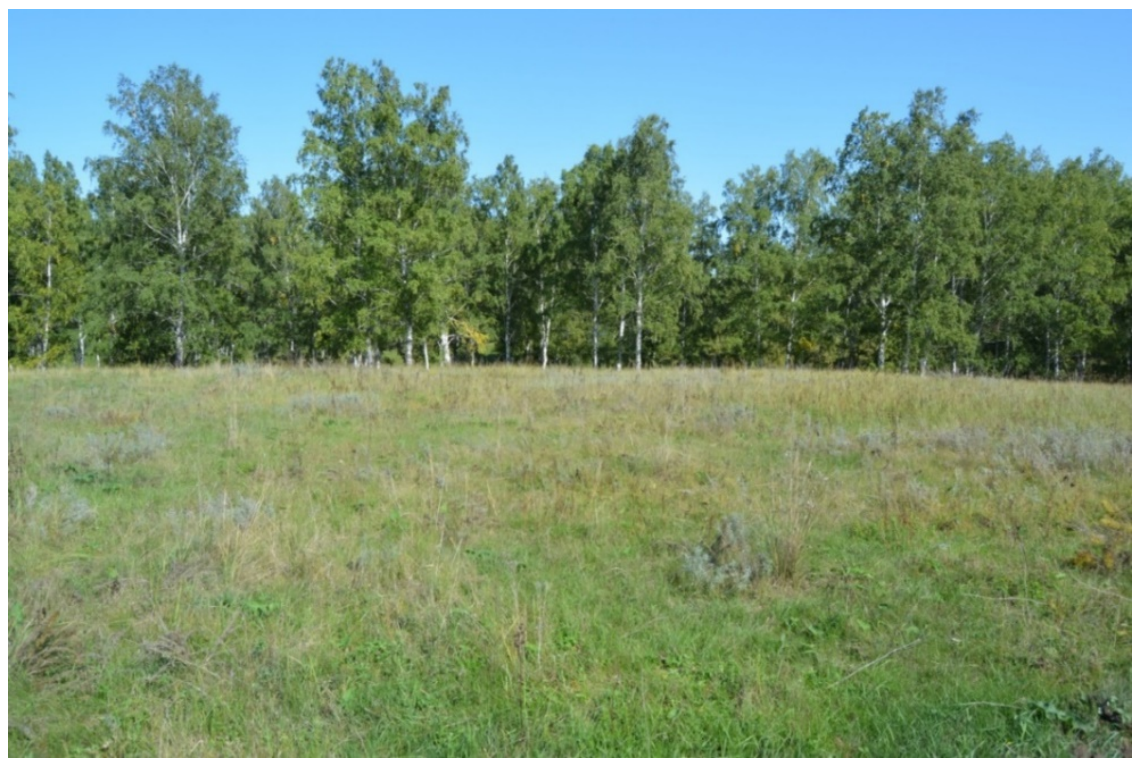

Fig. 4. Vegetation cover on site No. 6 (control).

Thus, in the studied sites, a total of 76 plant species were recorded, a significant part of which are ruderal species.

\section{Conclusion}

1. During the field survey of the reclaimed sites, it was found that when sowing perennial grasses (Bromopsis inermis, Medicago sativa, etc.) or planting arboreal and shrubby vegetation (Hippophae rhamnoides, Pinus sylvestris, etc.) on the dumped surface of the root layer from the PFR and/or FSL, favorable conditions for the formation of the primary phytocenosis are created in the reclaimed areas. Thus, in the studied areas, which are seven years old, the projective cover is $80-90 \%$ and approaches the projective cover in undisturbed areas $(95 \%)$.

With an increase in the age of reclamation, an increase in species diversity is noted - up to 18 species (in which a high proportion of aboriginal species is found), provided that this indicator fluctuates in different periods of time, as a result of the gradual replacement of annual plant species with perennial ruderal species and their simultaneous replacement with aboriginal species. The evidence of intensive processes of restoration of disturbed phytocenoses is the restoration of the biocenosis, the settlement of these territories by animal population, in particular, a significant number of anthills and underground passages of rodents were found in the investigated areas aged seven years or more.

2. On the site without PFR and FSL (No. 1), a significant species diversity was recorded - 20 species with a projective cover of no more than $7 \%$, which indicates the initial stage of succession. The arboreal and shrub layers are represented by several specimens of Acer negundo, Pinus sylvestris, Populus nigra, and Hippophae rhamnoides, and the herbaceous layer is represented by forbs of ruderal species. A significant part of the plants on this site is in a very depressed state, which is caused by the unfavorable physical properties of the substrate of the root layer.

3. The conducted studies have shown that the best values of the soil-ecological state of the reclaimed areas were obtained in options with the use of a fertile soil layer for the 
formation of a root layer. In such areas, a stable vegetation cover is formed and a gradual restoration of soil properties in the surface dumped layers is recorded close to the natural soils common in adjacent territories, and the restoration of the entire biocenosis has an active character.

The research was carried out with the financial support of the Russian Foundation for Basic Research and the Kemerovo Region within the framework of the scientific project No. 20-44-420006 220. Field research was carried out within the framework of expeditionary work according to the planned assignments of the Institute of Soil Science and Agrochemistry and Siberian State Industrial University.

\section{References}

1. W. Knabe, The Ohio Journal of Science, 64(2), 75-82 (1964)

2. V.A. Androkhanov, V.N. Kurachev, Soil-ecological state of technogenic landscapes: dynamics and assessment (Novosibirsk, 2010)

3. A.M. Shipilova, I.S. Semina, Izv. of the Ural State Mining Univ., 3(47), 53-56 (2017)

4. Yu.A. Manakov, O.A. Kupriyanov, Coal, 7(1120), 89-94 (2019)

5. T.S. Chibrik, Bulletin of Orenburg State Agrarian University, 5(37), 216-218 (2012)

6. T.S. Chibrik, N.V. Lukina, et al., Industrial botany, 19(3), 45-48 (2019)

7. M.A. Zhang, et al., Land Use Policy, 86, 375-386 (July 2019)

8. A. Adeli, et al., Soil Science, 178(7), 335-343 (July 2013)

9. B. Bond-Lamberty, A. Thomson, Nature, 464(7288), 579-582 (2010)

10. A. Bradshaw, Ecological Eng., 8(4), 255-269 (1997)

11. R.B. Finkelman, Int. J. of Coal Geology, 59, 19-24, (2004)

12. S. Mukhopadhyay, et al., Science of the Total Environment, 542, 540-550 (2016)

13. I.V. Zenkov, et al., Ecology and Industry of Russia, 22(2), 40-45 (2018)

14. 14. I.S. Semina, et al., GIAB, 9, 159-175 (2020)

15. I.S. Semina, et al., Science-intensive technologies for the development and use of mineral resources, 6, 439-444 (2020)

16. S. Soloviev, et al., E3S Web of Conferences, 244, (2021) 